\title{
POOL SAJANDIT JOHANNES VOLDEMAR VESKI PÄEVI
}

\author{
JÜRI VALGE
}

Annotatsioon. Viiekümne aasta jooksul igal aastal korraldatud Johannes Voldemar Veski päev on kujunenud Eesti keeleteadlaste oluliseks foorumiks. Neil on peetud ettekandeid peaaegu kõikide eesti keele valdkondade kohta, eelistuseks tänapäeva eesti kirjakeele struktuur ja areng. Viimastel aastatel on lisandunud keelepoliitika ja eesti keele arengukavadega seonduv ning arvutilingvistikat käsitlevad teemad. Keelekonverentsidel osalejate arv on vähehaaval kasvamas nagu ka neil esitatavate ettekannete arv.

Võtmesõnad: Johannes Voldemar Veski, eesti keel, keelekonverents

Et teeneka keelemehe 95. sünnipäevaks (27. VI 1968) ette valmistatavast konverentsist sai paraku mälestusüritus, millega pool sajandit tagasi alanud traditsioon kestab tänini, siis eeldavad selle iga ja toimumise stabiilsus vahekokkuvõtet. Kuna esimesest 20 aastast on Valve-Liivi Kingisepa ülevaade juba olemas (Kingisepp 1989), siis on järgnevas pearõhk eelkõige viimasel 30 aastal (vt ka Valge 2017) ja kahe perioodi võrdlusel.

Esimene, mida kahtlemata tuleb esile tõsta, ongi kõnealuste keelekonverentside korraldamise katkematus. Kui mitmesuguste ühenduste põhikirjajärgsed, liikmeskonnale määratud aastakoosolekud kõrvale jätta, siis pole ühtki teist soliidset avalikku keeleüritust (olgu selleks siis rakenduslingvistika või väikeste keelte konverentsid, keelefoorumid, õiguskeele, terminoloogia, teksti või keeleauhinna päevad), mis niisuguse toimumiskordade arvuni oleks jõudnud. Eraldi teema on muidugi eelkõige koolides toimunud keelepäevad (vt Oja 1990; Tender 2000), mida on seni korraldatud üle 300 korra (Laar jt 2017), kuid mis on esmajoones pedagoogilise suunitlusega. Püsiv on olnud Veski päeva toimumisaeg Veski sünnipäeval või siis paaril korral selle vahetus läheduses. Erandiks Veski 
ajakirjanikutööle pühendatud 4. konverents 1971. aastal Tallinnas, on päevad toimunud Tartus kas ülikooli peahoone 139., Johannes Voldemar Veski nime kandvas auditooriumis või mõnel korral ka senati saalis või aulas. Järgnevalt on esitatud ettekannete pidajad, pealkirjad ja pidamise aastad. ${ }^{1}$

Niina Aasmäe (1): Valdek Palli töödest mordva keelte alal (2012)

Ustus Agur $(* 1)$

Paul Ariste $(* 3)$

Eva Liina Asu-Garcia (vt Pire Teras, Eva Liina Asu-Garcia)

Annely Baran (1): Intensiivistavate väljendite kujundist - kas metafoorne võrdlus või hüperboolina kasutatav metonüümia (2007)

Kaily Cui, Karl Pajusalu (1): Sõnaalgulise $h$ hääldusest eesti keeles (1999)

Arvo Eek, Toomas Help (*1)

Martin Ehala (4): 1) Suhtluslävi - probleemid ja perspektiivid (1995)

2) Eesti keele muutumine korporatiivsest keelest avatud keeleks (1998)

3) Keelehoiakute kujundamine ja identiteediarendus (2003)

4) Keelekontakt veebis: näiteid varieerumisest sihitise kasutamisel (2010)

Mati Erelt: (vt ka Mati Erelt, Helle Metslang) (1): Emakeele Seltsi aastaraamatu „Eesti keele uurimise olukorra analüüs“ esitlus (2003)

Mati Erelt, Helle Metslang (2): 1) Oma või võõras (1998)

2) Imperatiivist eesti keeles (2004)

Tiiu Erelt $(* 4,3): 1)$ Eesti terminoloogia praegu (1993)

2) Keelekorralduse sõnaraamat (1997)

3) Praegune oskuskeelesituatsioon (2000)

Liis Ermus (1): EMSUKA heliarhiivi digitaalsed võimalused (2015)

Valts Ernštreits (vt Miina Norvik, Valts Ernštreits)

${ }^{1}$ Kokkuvõte on koostatud konverentsikutsete ning ülevaadete põhjal. Nime taga sulgudes on esinemiste arv. Kui esinenul on ettekandeid mõlemal perioodil, siis on esimesena esitatud ja tärniga tähistatud aastail 1968-1987 peetud ettekannete arv. Teisel kohal on perioodi 1988-2017 ettekannete arv. Info mitme autoriga ettekannete kohta tuuakse ühe esineja juures, teis(t)e autori(te) juures viidatakse põhiregistreeringule. Eelmise perioodi kokkuvõttesse ekslikult sattunud R. Karlson ja R. Kask on parandatud Rudolf Karelsoniks ja Reet Kasikuks. 
Andres Hallmägi, Tõnu Tender (1): 1934. ja 1995. a keeleseadused: ühist ja erinevat (2008)

Reet Hendrikson (1): Ikka sõja- ja kujundkeele ristteel (2017)

Toomas Help (vt Arvo Eek, Toomas Help)

Tiit Hennoste (vt ka Andriela Rääbis, Tiit Hennoste) (*1, 3): 1) Eesti keel kui sotsiolekt (1996)

2) Kuidas ajalehed manipuleerivad (2005)

3) Vabaduse tulemine. Eesti ajakirjandus ja tema keel Eesti Vaba riigi algusajul (2008)

Toivo Hinrikus (1): Farmaatsia oskussõnavarast (2000)

Mati Hint (*3)

Annika Hussar (1): Eestlaste eesnimed 1900. aastal (2009)

Kaido Jaanson (1): Mõned poolsubjektiivsed mõtted politoloogia ja poliitika keelest (2000)

Anne Jänese (1): Eesti keele kui riigikeele õpetamisest Tartu Ülikooli muukeelsetele üliõpilastele (1995)

Leo Jürgenson $(* 1)$

Ain Kaalep (1): Antiikluule tõlkimise küsimusi (1994)

Heiki-Jaan Kaalep (2): 1) Laiatarbe-arvutiprogrammid - eesti keeletehnoloogia õied (2002)

2) Morfoloogiline analüüs kui tehniline ülesanne (2015)

Marja Kallasmaa (1): Valdek Palli jälgedes ja sammuke kõrvale ka (2012)

Kristian Kankainen (1): EKI e-keelenõust (2015)

Rudolf Karelson (*2)

Karl Karlep (1): Kõnepuuete olemus ja avaldumine (2013)

Siim Karnö (vt Kadri Sõrmus, Siim Karnö)

Reet Kasik (*2, 4): 1) Kas ajalehekeel on astunud ämbrisse (1993)

2) Ajakirjanduskeel 21. sajandi alguses (2005)

3) Eesti keel ja keeleteadus Tartu ülikoolis 1919-1940 (2008)

4) Sõnamoodustuse tervikkäsitlus (2014)

Arnold Kask (*5)

Külliki Kask (1): Eesti keel eesti koolis: õpetaja vaatenurk (2006)

Petar Kehayov (1): Kaudne kõneviis tüpoloogilisest aspektist (2004)

Krista Kerge (*1, 4): 1) Omastavavorm eesti lauses (1992)

2) Mölder ja don Quijote keeleveskis (1993) 
3) Keele valdamise komponendid (1995)

4) Emakeel koolis: kelle mure (2006)

Annika Kilgi (1): Morfoloogiakirjelduse valikutest (2014)

Valve-Liivi Kingisepp (*3, 3): 1) Kolmkümmend kolm aastaraamatut ja mõnda, mis seal sees leida on (1990)

2) J. V. Veski võõrkeeled ja tõlketegevus (1994)

3) Vana kirjakeele sõnaraamat (1997)

Birute Klaas-Lang (2): 1) Possessiivsed konstruktsioonid Balti keeleareaalis (1992)

2) Kas eestikeelsel rahvusülikoolil on tulevikku? (2011)

Ekaterina Kornilitsina (1): Metafooride tõlkimisest kognitiivse keeleteaduse seisukohalt (2017)

Einar Kraut (1): Hääldusnormist (1999)

Tiit Kukk (1): Adverbi moodustus karjala keeles (1988)

Rein Kull (*6)

Ott Kurs (1): Maateaduse terminoloogia arendamisest 1920. aastail (2008)

Jakob Kübarsepp (1): Eesti keel õppe- ja teaduskeelena tehnikahariduses (2008)

Ago Künnap (*1)

Heli Laanekask (2): 1) Läänemeresoome keelte võrdleva uurimise esimesed sammud Eestis (1988)

2) Eesti kirjakeele ajaloo tervikkäsitlusest (2016)

Arvo Laanest (*1)

Margit Langemets (2): 1) Leksikograafi unistus (2007)

2) EKI keelevara ja moodne aeg (2015)

Mall Laur $(* 1)$

Helle Leemets $(* 1)$

Tiina Leemets (1): Eesti keelekorralduse sõnaraamat (1993)

Eerik Leibak (1): Maailma lindude eestikeelsetest nimedest (2000) Merle Leppik (*1)

Krista Leppikson (1): Kuidas on ja kuidas võiks. Keeletoimetaja mõtteid (2005)

Liina Lindstöm (2): 1) Narratiivi sõnajärjest (1998)

2) TÜ eesti murrete ja sugulaskeelte arhiiv ning murdekorpus uurimisvõimaluste avardajana (2012)

Mihhail Lotman (1): Tõlke kulturoloogilistest aspektidest (1994) 
Chris-Evelin Luik (1): Gümnaasiumilõpetaja emakeeleoskuse kontrollimisest (2006)

Viivi Maanso (1): Võõrsõnatarvitus eesti õppekirjanduses (1991)

Tiit Masso, Priit Silla $(* 1)$

Einar Meister (1): Eesti keele foneetiline andmebaas (1999)

Uno Mereste (*1)

Henno Meriste (*2)

Helle Metslang (vt ka Mati Erelt, Helle Metslang) (4): 1) Tuleviku viitamise viisidest eesti ja soome keeles (1992)

2) Kirjakeele nüüdisseisundist ja tulevikuvaadetest seisundiuuringute põhjal (2003)

3) Grammatikamuutuste sammud ja hüpped (2010)

4) Mis teoksil: eesti keele tervikkäsitlused ja akadeemiline grammatika (2014)

Meelis Mihkla (2): 1) Kas eesti keelel on infoühiskonnas tulevikku? (2002)

2) Subtiitrite helindamine - kas, kuidas, kellele ja miks? (2013)

Kadri Muischnek (vt ka Kadri Muischnek, Heili Orav) (2): 1) Automaatne süntaksianalüüs ja analüsaatori veebiliides (2015)

2) Püsiühendid keeleressurssides (2017)

Kadri Muischnek, Heili Orav (1): Eesti keele korpused ja arvutileksikonid - mis on olemas ja mida veel vaja on? (2002)

Mari Must $(* 1,1)$ : Emakeele Selts ja eesti murded (1990)

Sirje Mäearu (1): Topeltdeminutiividest (1991)

Mart Mäger (1): Refleksiivid - sajandi järjekestvus (1991)

Johannes Mäll $(* 1)$

Harri Mürk (1): Väliseestlase emakeel: tänapäev ja tulevik (1989)

Raul Narits (1): Keele sõnavara ja selle seos Eesti õiguskorraga (2000)

Helmi Neetar $(* 1,1)$ : Miks eesti murretes varieerub deverbaalide käänamine (1991)

Miina Norvik, Valts Ernštreits (1): Uus liivi grammatika (2016)

Tiiu Ojanurme (1): Emakeele Seltsi ajakiri „Eesti Keel“ 1922-1940 (1990)

Mare Onga $(* 1)$

Heili Orav (vt Kadri Muischnek, Heili Orav)

Ervin Org (vt Karl Pajusalu, Ervin Org, Eva Velsker)

Marika Padrik (1): Kui laps õpib emakeelt nagu võõrkeelt ...? (2013) 
Hille Pajupuu (*1, 1): Eesti intonatsioonist (1999)

Karl Pajusalu (vt ka Kaily Cui, Karl Pajusalu; Karl Pajusalu, Ervin Org, Eva Velsker; Karl Pajusalu, Renate Pajusalu) (1): Eduard Vääri liivi keele ja kultuuri uurijana (2016)

Karl Pajusalu, Ervin Org, Eva Velsker (1): $n$-inessiivi levik KeskVõru keelepruugis (1996)

Karl Pajusalu, Renate Pajusalu (1): Tingiv kõneviis argivestluses (2004)

Renate Pajusalu (vt ka Karl Pajusalu, Renate Pajusalu) (1): Kui dialoog veab viltu (1992)

August Palm (*1)

Sirli Parm (1): Sõnade veel, juba, alles ja jälle ajaline tähendus (2007) Jaak Peebo $(* 2)$

Juhan Peegel $(* 1,1)$ : Iseendaks jäämisest $(120$ aastat J. V. Veski sünnist) (1993)

Pille Penjam (1): Jussiivist vanas kirjakeeles (2004)

Ants Pihlak (1): Umbisiku kaitseks (1992)

Külli Prillop (1): Sõnade ja vormide esmaesinemused vanas kirjakeeles (2016)

Peeter Päll (2): 1) Nimed uuenevas maailmas (1989)

2) Mitmekeelsus Eesti nimedes (2009)

Raimo Raag (1): Eesti keele õpetus Rootsis: minevik, olevik, pilk tulevikku (1990)

Erich Raiet $(* 1)$

Lehte Rannut (*1)

Mart Rannut (1): Keelenihe ja tasakaal (1996)

Mart Remmel, Ülle Viks (*1)

Richard Ritsing (*1)

Anne Romet, Ülle Viks (1): Eesti-vene sõnaraamat (1997)

Eevi Ross (1): Emakeele Seltsi 174 keelepäeva: kas vähe või palju, kas tarvilikud või tarbetud? (1990)

Kristiina Ross (1): Ülemlaulu tõlkest esimeses eestikeelses piiblis (1994)

Ingrid Rummo (1): Düspraksia - kõnetu inimene suhtluses (2013) Maia Rõigas (1): Eesti keele õpetajate ettevalmistus Tartu ülikoolis (2006)

Huno Rätsep $(* 6,1)$ : Uute tüvede saamisviisid eesti keeles (1991) 
Andriela Rääbis, Tiit Hennoste (1): Suuline eesti keel. Tervikkäsitluse sisukord (2014)

Evar Saar (2): 1) Paljukeelsus ja silmahakkavad nimeandmispõhimõtted internetiajastu katastrinimedes (2009)

2) Viru kohanimede erinevaid tüüpe (2012)

Riho Saard (1): Luterliku kiriku eestistamisest (2008)

Henn Saari (*4, 3): 1) Eesti keel siin ja täna (1989)

2) Paragrahv kolmkümmend (1993)

3) Vanu vaateid keele muutumisele (1998)

Jüri Salme (*1)

Joel Sang $(* 1)$

Kathy Sarapuu (1): Päevalehtede juhtkirjad tekstina (2005)

Maria-Maren Sepper (1): Jussiivist tänapäeva kirjakeeles (2004)

Priit Silla (vt Tiit Masso, Priit Silla)

Leeni Simm (1): Häälikusümboolika keele ,perifeerias“ (1988)

Mihhail Stalnuhhin (1): Eesti keele areng lähitulevikus: kiire muutumine või mutatsioon (2001)

Urmas Sutrop (1): Kuidas tüpoloog kirjeldaks eesti keele sõnavara (2007)

Kadri Sõrmus, Siim Karnö (1): Emakeeleõppija korpus EMMA ja mõnda, mis seal sees leida on (2015)

Kaja Tael (1): Eesti ja soome sõnajärjest (1988)

Mall Tamm (1): Konverentsitõlke probleeme Eestis (1994)

Arvi Tavast (1): Olukorrast ja probleemidest arvutialal (2000)

Tõnu Tender (vt ka Andres Hallmägi, Tõnu Tender) (1): Hunt lambanahas? Võõrkeeled eesti keele arengukavas (2011)

Pire Teras, Eva Liina Asu-Garcia (1): Foneetika tervikkäsitlus (2014)

Ilmar Tomusk (1): Keeleseaduse täitmise järelevalve valupunkte (2001)

Kristjan Torop (*1)

Peeter Torop (1): Tõlgitavuse parameetritest (1994)

Juhan Tuldava $(* 1)$

Evald Tõnisson (1): Lisandeid läänemeresoomlaste kultuurilise ja etnilise ajaloo uurimisele (1990)

Ellen Uuspõld (*3)

Lembit Vaba (2): 1) Etümoloogiasõnaraamat (1997)

2) Keelekontaktid ja eesti keele grammatika (2010) 
Ene Vainik (1): Eesti väliskohakäänded - näiteid grammatika semantikast (1992)

Jüri Valge $(* 1,4)$ : 1) Eesti keel võõrkeelena Tartu Ülikoolis alates 1989. aastast (1995)

2) Avalikkus emakeelest (2001)

3) Eesti keele arendamise strateegia ja selle koostamine (2003)

4) Eesti keele arengukava esimene pool aastat (2011)

Aino Valmet $(* 1)$

Helju Vals $(* 1)$

Kadri Vare (1): Keeleressurssidest Eesti keeleressursside keskuses ja keeletehnoloogia saavutustest riikliku programmi raames (2015)

Silvi Vare $(* 1,3)$ : 1) Verbi ja deverbaali vahekorrast (1991)

2) Eesti keel vene üldhariduskoolis (1995)

3) Keeleõppepoliitikast ja eesti keele õppimisest teise keelena (2001)

Ann Veismann (2): 1) Värske pilk määrusele (2014)

2) Ajametafooridest eesti keeles (2017)

Enn Veldi (2): 1) Pejoratiivsus ja häälikusümboolika informaalses sõnaraamatus (2007)

2) Inglise laenudest eesti keeles Euroopa kontekstis (2010)

Eva Velsker (vt Karl Pajusalu, Ervin Org, Eva Velsker)

Anna Verschik (2): 1) Eesti juutide mitmekeelsuse põhijooni (1996)

2) Keelepoliitika ja „muulaste“ hoiakud (2011)

Asta Veski $(* 1)$

Triin Vihalemm (1): Muulaste hoiakud eesti keele suhtes (1993-1995) (1996)

Helgi Vihma $(* 1)$

Jüri Viikberg (2): 1) Saksa keelest eesti keeles (2010)

2) Murdesõnaraamat 1922-2012 (2012)

Tiit-Rein Viitso $(* 1,2)$ : 1) Kus kujunes läänemeresoome häälikurühm? (1990)

2) Eesti keele häälikuloost sugulaskeelte taustal (2016)

Ülle Viks (vt ka Anne Romet, Ülle Viks; Mart Remmel, Ülle Viks)

$(* 3,1)$ : Mis kasu on keeleteadusele keeletehnoloogiast? (2002)

Piret Voolaid (1): Kujundiloomest eesti mõistatuste alaliikides (2017)

Eduard Vääri (*1, 1): Kui keelemees J. V. Veski elaks meie ajal (2001)

Asta Õim (1): Kujundsõnast eesti fraseoloogias (2017) 
Katre Õim (1): Metafoor ELU ON TEEKOND ebaõnne väljendite näitel (2007)

Toom Õunapuu (1): Suundumusi ja tendentse eesti keele õppekirjanduses venelastele (1995)

Seniseil andmeil on peetud 233 ettekannet - esimesel 20 aastal 83 (arvestatud pole Kingisepa ülevaates ettekandeiks loetud Paul Ariste, Arnold Kase ja Helju Valsi 4 ava- ja lõppsõna), aastail 1988-2017 aga 150. Ava- ja lõppsõnu pole arvesse võetud hiljemgi, küll aga on ettekandeiks loetud konverentsikutsel eraldi kirjas olnud ESA 48, „Eesti keele uurimise analüüsi“ esitlus Mati Erelti poolt 2003. a ning teistest ettekannetest eraldi seisvana Juhan Peegli „Iseendaks jäämisest (20 aastat J. V. Veski sünnist)“ 1993. a. Ettekandeid on kuulanud üle $3000 \mathrm{~J}$. V. Veski ja eesti keele austaja.

Suurema osavõtjate arvuga konverentsid on toimunud 2001 („Eesti keelepoliitikast“", 100 osavõtjat), 1993 („Eesti keelehoole“, 98 osalejat), 1995 („Eesti keel võõrkeelena“, 97 osalejat) ja 1994 („,Tõlkimine - võit ja kaotus", 94 osalejat). Selgelt osavõturohkeim on kindlasti olnud J. V. Veski 100. sünniaastapäevale pühendatud kuues konverents 27. juunil 1973 (175 osalejat): sellega seotud üritused kestsid mitu päeva ning lisaks pühendas Keele ja Kirjanduse Instituut Veski sünniaastapäevale veidi varem Tallinnas peetud läänemeresoome filoloogia sümpoosioni. Konverentsipäeval sai ülikooli peahoone 139. auditoorium rektori käskkirjaga ka akadeemiku nime ning seal avati tema pronksbüst (autor Ülo Õun). Veel enne seda oli 24. juunil avatud mälestuskivi Veski sünnikohas Vaidaveres (autor Ants Mölder) ja 26. juunil tahvel tema viimases elukohas Tartus Vabriku 5.

Konverentsid on muutunud osavõturohkemaks ja pikemaks: esimesel perioodil keskmiselt ligi 60 osalist (koos eelmainitud 6. konverentsiga üle selle), teisel juba üle 60; esimesel perioodil tuli konverentsi kohta keskmiselt veidi üle 4 ettekande, teisel ligi 5. Mainitagu, et nii ettekannete kui ka osalejate arv on korduvast kokkulugemisest hoolimata ligikaudsed: kohati ei vasta kutsel olev kava tegelikult toimunule (mõni ettekanne, küll ülimalt harva, on ära jäänud, mõni väljastpoolt kava juurde peetud), erineva põhjalikkusega on koostatud konverentsiülevaated ESAs ning Keeles ja Kirjanduses, kohati ülestähendusi lihtsalt napib. Erineva kaalu ja kestusega on olnud ava- ja lõppsõnad ning kindlasti on osalejaid olnud registreeritust rohkem.

Silmatorkavalt lai on olnud Emakeele Seltsi juhatuse kavandatud Veski päevade temaatika, mis on hõlmanud otse või kaudselt eesti keele 
ja keeleelu peaaegu kõiki valdkondi (alates 11. konverentsist on iga Veski päev olnud pühendatud mingile kindlale teemale). Nähtavasti pole siiski otstarbekas üritada teemasid seostada käsitluste arvuga - üks ja sama ettekanne on võinud haarata mitutki eri valdkonda. Küll aga võib osutada mõningatele teist kokkuvõtteperioodi esimesest eristavatele suundumustele ja nende põhjustele.

Enim käsitletud teemaks on mõlemal perioodil olnud tänapäeva eesti kirjakeele kui terviku või mõne selle osa struktuur ja areng (sh koostatavate eesti keele akadeemiliste tervikkäsitlustega seostuv), samuti keelekorralduse ning terminoloogia probleemid. Tõsi, keelekorraldusest on teisel perioodil mõistetavalt veidi vähem räägitud, sest ÕSide koostamisega kaasnenud vaidlusigi on mõnevõrra vähemaks jäänud. Ettekandeainet on pakkunud ka tähtpäevad ja keeleelu aktuaalsed sündmused: Emakeele Selts 70, Tartu ülikool 350, VI fennougristika kongress Sõktõvkaris (sel puhul käsitleti soome-ugri keeleteadust Eestis), XI rahvusvaheline foneetikakongress Tallinnas (ajendas ettekandeid eesti keele hääldusprobleemidest) jm.

Lisandunud on teemad, mille käsitlemine enne Eesti taasiseseisvumist oli keeruline, võimatu või puudus käsitlusobjekt üldse: keelepoliitika, eesti keele seisundikirjeldused, arengukavad ja nende elluviimine. Ka eesti keele kontaktide ja Eestis esindatud keelte kirjeldamisel on olnud võimalik esile tuua aspekte, mida varem polnud uuritud või mille käsitlemine ei olnud eriti soovitatav. Kui arvutikasutusel põhinevat keeleuurimist käsitlevaid ettekandeid oli esimesel analüüsiperioodil vaid 3 (Mart Remmel, Ülle Viks), siis aastail 1988-2017 on nende arv peaaegu neljakordistunud.

Mille arvelt need uued teemad on tulnud? Silmatorkav on, et oluliselt on vähenenud J. V. Veski eesti keele alase tegevuse (eelkõige keelearendus- ja terminoloogiatöö) analüüs. Kuigi üksikuid käsitlusi on olnud hiljemgi ning võib tulla veelgi, on olulisem osa Veski tööst paarikümne aasta jooksul, möödunud sajandi kuuekümnendatest kaheksakümnendateni üldjoontes üle vaadatud. Vähenenud (vähemalt suhteliselt) on ka vana kirjakeelt, murdeid ja sugulaskeeli käsitlevate ettekannete arv. Ebaloomulikult vähe on räägitud tõlkeprobleemidest.

Poolesajast varasema perioodi esinejast pidas kümme ligi poole ettekannetest. „Suur on olnud Emakeele Seltsi omaaegsete esimeeste A. Kase ja H. Rätsepa roll, korduvalt on esinenud R. Kull, P. Ariste, T. Erelt, H. Saari, Ü. Viks, M. Hint, E. Uuspõld jt.“ (Kingisepp 1989; iseenda on 
selles loetelus jätnud Kingisepp mainimata). Viimasel kolmekümnel aastal on ettekandepidajate seltskond uuenenud ja nende suhteline panus esinejate arvu suurenemise tõttu vähenenud, kuigi absoluutarvud pole eriti muutunud: kaheteistkümne enam kui kolm ettekannet pidanud esineja osaks jääb veidi rohkem kui veerand ettekandeist. Sagedamini esinenute hulka kuuluvad Martin Ehala, Mati Erelt, Tiiu Erelt, Tiit Hennoste, Reet Kasik, Krista Kerge, Valve-Liivi Kingisepp, Helle Metslang, Karl Pajusalu, Henn Saari, Jüri Valge ja Silvi Vare. Mõlemasse loetellu on jõudnud Tiiu Erelt, Valve-Liivi Kingisepp ja Henn Saari. Kokkuvõttes võib nentida, et 50 aasta jooksul on Veski päeval üles astunud oluline osa eesti keele uurimise, arendamise ja õpetamisega kokku puutunud või puutuvatest inimestest. Tähelepanuväärselt on esinejate hulgas olnud muusika, õigusteaduse, geograafia, tehnika ning teiste alade esindajad, mis osutab käsitletud keelekasutusvaldkondade hulgale. Konverentside juhtimise ning ava- ja lõppsõnade ütlemise au on üldjuhul kuulunud Emakeele Seltsi juhatuse esimeestele.

Ettekanded on kahtlemata andnud vajalikku ja huvitavat infot kõigile poolesajast Veski päevast osavõtnuile, kuid need on olnud tähtsad ka esinejaile endile, pakkudes võimalust valminud või valmivaid uurimusi tutvustada. Viimasel puhul on arutelu sageli aidanud veel lahendamata küsimustele vastuseid otsida. Mõnigi ettekanne on leidnud avaldamist keeleväljaannetes, eelkõige Emakeele Seltsi aastaraamatutes. „Aastakonverents - J. V. Veski päev, on kujunenud Eesti keeleteadlastele kõige olulisemaks foorumiks, "kirjutab Jüri Viikberg riigisekretär Ülo Kaevatsile (Viikberg 1993).

Traditsioonilised on olnud lillede panek, tänusõnavõtt ja -laul akadeemiku kalmul ning aastaid tagasi Asta Veski meeleolukad vastuvõtud Veskite Vabriku tänava kodus. Asta Veski asutas 1995. a ka oma isa mälestusfondi, millest aastail 1996-2000 ning 2002, 2009 ja 2011 jagatud stipendiumidega on toetatud kümmet eesti keelt peaainena õppivat 3. või 4. aasta üliõpilast või magistranti. Stipendiaatide nimed tehti teatavaks Veski päeval. Samuti on Veski päeval esitletud Emakeele Seltsi aastaraamatut ja muid olulisi, ESi toetusel valminud väljaandeid. 


\section{Kirjandus}

Kingisepp, Valve 1989. 20 J. V. Veski päeva. - Emakeele Seltsi aastaraamat 33 (1987). Keelest ja kultuuriloost. Tallinn: Eesti Raamat, 140-143.

Laar jt 2017 = Triinu Laar, Andra Rumm, Kätlin Aare. „Ma sain täna teada, et eesti keelel on veel lootust püsima jääda.“ - Oma Keel 1, 86-91.

Oja, Vilja 1990. 23. J. V. Veski päev. - Keel ja Kirjandus 9, 575-576.

Tender, Tõnu 2000. Emakeele Seltsi keelepäevad 1961-1999: trepp elevandiluust tornist maale. - Emakeele Seltsi aastaraamat 44-45 (1998-1999). Tartu, 123-134.

Valge, Jüri 2017. Viiskümmend aastat Veski päevi. - Oma Keel 2, 89-93.

Viikberg, Jüri 1993. Kiri riigisekretär Ülo Kaevatsile. - Emakeele Seltsi kirjavahetus: $7-1 / 5 ; 27$. I. 


\title{
Half a century of Johannes Voldemar Veski days
}

\author{
JÜRI VALGE
}

On June 27, 1968, the Mother Tongue Society held an event dedicated to the memory of Johannes Voldemar Veski.. This developed into an annual language conference - the tradition of Veski Day. On June 27, 2017, the 50th annual Veski Day was held. The first twenty Veski Days have been summarized by Valve-Liivi Kingisepp (1989), and this article gives an overview primarily of the following 30 years. Veski Day has become one of the most important forums for Estonian linguists. The total number of participants exceeds 3000 , remaining fairly stable year-to-year with a trend of moderate growth. A total of 232 presentations have been given, typically 4-6 per conference.

The most popular topics at the conferences have been the structure and development of modern Estonian, language planning and terminology issues. While the earliest conferences focused more on topics related to Veski's work, the history of old written Estonian, dialects, and kindred languages, later years have seen an increased emphasis on topics related to language policy, the Estonian language development plan, language contacts and computational linguistics.

On J.V.Veski Day, stipendia have been given from the remembrance fund in his name founded by Asta Veski, and the annual Mother Tongue Society yearbook and other important publications financed by the Mother Tongue Society have been presented.

Keywords: Johannes Voldemar Veski, Estonian language, language conference

Jüri Valge

keelekorraldusosakond

Eesti Keele Instituut

Roosikrantsi 6

10119 Tallinn

juri.valge@ut.ee 